\title{
PENERAPAN MODEL PEMBELAJARAN DISCOVERY UNTUK MENINGKATKAN HASIL BELAJAR SISWA PADA PEMBELAJARAN PENDIDIKAN KEWARGANEGARAAN
}

\author{
Didi Junaedi \\ SD Negeri 2 Girinata Cirebon, Indonesia \\ didijunaedi12@gmail.com
}

\begin{abstract}
This study began with the problem of low student learning outcomes in the Civics Education subject. The author tries to overcome these problems by trying to apply the Discovery learning model. This study aims to improve student learning outcomes in Civics subjects in the material "Fighting Values in the Formulation of Pancasila" with the application of the Discovery learning model. This research is a Classroom Action Research (CAR), which was conducted in 2 cycles with research subjects of Grade VI students of SD Negeri 2 Girinata, Dukupuntang District, Cirebon Regency. The results showed the average student learning outcomes in Civics learning on the material "Fighting Values in the Formulation of Pancasila" increased. Thus it can be concluded that the application of discovery learning models can improve student learning outcomes in Civics learning.
\end{abstract}

Keywords: discovery learning models, learning outcomes, civics.

\section{ABSTRAK}

Dalam pelaksanaan pembelajaran seni rupa banyak siswa kelas yang belum menguasai Penelitian ini berawal dari permasalahan rendahnya hasil belajar siswa pada mata pelajaran Pendidikan Kewarganegaraan (PKn). Penulis berupaya mengatasi permasalahan tersebut dengan mencoba menerapkan model pembelajaran Discovery. Penelitian ini bertujuan untuk meningkatkan hasil belajar siswa pada mata pelajaran PKn pada materi "Nilai Juang dalam Proses Perumusan Pancasila" dengan penerapan Model pembelajaran Discovery. Penelitian ini merupakan Penelitian Tindakan Kelas (PTK) yang dilaksanakan sebanyak 2 siklus dengan subyek penelitian siswa kelas VI SD Negeri 2 Girinata Kecamatan Dukupuntang Kabupaten Cirebon. Hasil penelitian menunjukkan rata-rata hasil belajar siswa dalam pembelajaran PKn pada materi "Nilai Juang dalam Proses Perumusan Pancasila" meningkat. Dengan demikian dapat disimpulkan penerapan model pembelajaran discovery dapat meningkatkan hasil belajar siswa pada pembelajaran PKn.

Kata Kunci: model pembelajaran discovery, hasil belajar, PKn.

Submitted Feb 22, 2020 | Revised Mar 23, 2020 | Accepted Mar 24, 2020

\section{Pendahuluan}

Pendidikan Kewarganegaraan (PKn) merupakan salah satu mata pelajaran yang diajarkan dilembaga pendidikan formal diantaranya pelajaran Bahasa, IPA, IPS, Agama, Matematika, Penjasorkes dan sebagainya. Pendidikan Kewarganegaraan merupakan mata pelajaran yang mefokuskan pada pembentukan warga negara yang memahami dan mampu melaksanakan hak dan kewajiban untuk menjadi warga negara Indonesia yang cerdas, terampil, berkarakter yang diamanatkan oleh Pancasila dan UUD 1945 (Depdiknas, 2006:49). Somantri (2001) menyatakan bahwa, PKn merupakan usaha untuk membekali peserta didik dengan pengetahuan dan kemampuan dasar yang berkenan dengan hubungan antar warga negara 
dengan negara serta pendidikan pendahuluan bela negara menjadi warga negara agar dapat diandalkan oleh bangsa dan Negara.

Pembelajaran PKn dapat dikatakan berhasil apabila siswa dapat menyelesaikan tugas atau penilaian yang dilakukan oleh guru. Alat penilaian yang digunakan oleh guru harus dapat menjaring kemampuan kognitif, afektif, dan psikomotor sesuai dengan taksonomi Bloom. Dengan demikian penilaian yang dilakukan guru tidak hanya berupa penilaian tertulis namun juga dapat dilihat dari sikap siswa setelah memperoleh materi.

Kenyataan yang terjadi di lapangan saat ini bahwa guru dalam mengajar Pendidikan Kewarganegaraan masih senantiasa mengajar tanpa memperhatikan karateristik siswa dan masih menganggap siswa tersebut adalah orang dewasa. Disisi yang lain, guru dalam proses pembelajaran masih senantiasa menggunakan metode, pendekatan dan strategi yang masih berpusat pada guru sehingga siswa dalam pembelajaran kurang aktif dan membosankan. Atas dasar ini, perlunya guru melakukan pendekatan dan strategi dalam pembelajaran yang sesuai dengan kondisi dan perkembangan siswa agar tujuan pembelajaran dapat dicapai.

Berdasarkan pengamatan awal terhadap proses pembelajaran Pendidikan Kewarganegaraan (PKn) di kelas VI SD Negeri 2 Girinata Kecamatan Dukupuntang Kabupaten Cirebon dan diskusi dengan para guru serta kepala sekolah, tentang mata pelajaran PKn teridentifikasi masalah nyata sebagai berikut: (1) siswa menganggap mata pelajaran PKn menjemukan karena berisi konsep-konsep yang harus dihafal; (2) siswa hafal konsep-konsep dalam PKn, tetapi tidak memahami maknamya (verbalisme); (3) siswa memahami konsep, akan tetapi tidak mampu menerapkan konsep dalam memecahkan masalah; (4) siswa kurang mampu mengemukakan pendapat secara sistematis, baik lisan maupun tulisan; (5) siswa tidak terbiasa untuk berbeda pendapat, berdebat, dan mengambil keputusan yang terbaik bagi dirinya dan orang lain; (6) guru berorientasi pada target hasil penguasaan materi, sehingga seringkali mengabaikan bagaimana proses belajar siswa menuju penguasaan materi.

Permasalahan di atas bisa diatasi melalui kemauan keras guru PKn untuk memperbaiki desain dan strategi pembelajaran, dan berkolaborasi dengan guru-guru SD Negeri 2 Girinata Kecamatan Dukupuntang Kabupaten Cirebon untuk mengkaji strategi pembelajaran apa yang tepat dan eafektif untuk diterapkan, sehingga mampu memperbaiki kondisi tersebut. Oleh karena itu, perlu penelitian tindakan kelas yang dilakukan oleh penulis bersama guru-guru SD Negeri 2 Girinata Kecamatan Dukupuntang Kabupaten Cirebon. Salah satu model pembelajaran yang dianggap efektif dalam mengatasi permasalahan yang disebutkan di atas adalah Model pembelajaran Discovery.

Menurut Kurniasih, dkk (2014) model discovery learning adalah proses pembelajaran yang terjadi bila pelajaran tidak disajikan dengan pelajaran dalam bentuk finalnya,tetapi diharapkan siswa mengorganisasikan sendiri. Discovery adalah menemukan konsep melalui serangkaian data atau informasi yang diperoleh melalui pengamatan atau percobaan. Pembelajaran dengan discovery learning dapat membantu guru dalam mengolah proses pembelajaran menjadi lebih efisien dan efektif terutama memberikan kemampuan peserta didik dalam membangun kolaboratif dan memilki komitmen nilai yang tinggi dalam keaktifan belajar (Ariani \& Wachidi, 2019). Keunggulan Discovery Learning dan kesesuaiannya dengan pendekatan ilmiah dari kurikulum 2013, dikombinasikan dengan metode mendengarkan tiga fase akan membantu siswa untuk menemukan materi pembelajaran yang ditargetkan sendiri (Hanafi, 2016). 
Model discovery learning ini dalam prosesnya menggunakan kegiatan dan pengalaman langsung sehingga akan lebih menarik perhatian anak didik dan memungkinkan pembentukan konsep-konsep abstrak yang mempunyai makna, serta kegiatannya pun lebih realistis (Ilahi, 2012). Kegiatan penemuan yang dilakukan oleh manusia itu sendiri dan dilakukan secara aktif akan memberikan hasil yang paling baik, serta akan lebih bermakna bagi dirinya sendiri (Bruner dalam Sujana, 2014). Beberapa hasil penelitian yang telah dilaksanakan, diantaranaya penelitian Laksana (2018), Sulfemi dan Yuliana (2019), Reinata (2019), dan Purwini (2019), menunjukkan model pembelajaran Discovery berhasil meningkatkan hasil belajar dan motivasi belajar siswa dalam pembelajaran PKn.

Penelitian ini akan difokuskan pada upaya untuk mengatasi faktor internal yang diduga menjadi penyebab rendahnya tingkat kemampuan siswa kelas VI SD Negeri 2 Girinata Kecamatan Dukupuntang Kabupaten Cirebon, dalam memahami mata pelajaran PKn, yaitu kurangnya inovasi dan kreativitas guru dalam menggunakan metode pembelajaran sehingga kegiatan pembelajaran PKn berlangsung monoton dan membosankan. Salah satu metode pembelajaran yang diduga mampu mewujudkan situasi pembelajaran yang kondusif, aktif, kreatif, efektif, dan menyenangkan adalah Model Discovery.

\section{Metode Penelitian}

Metode penelitian yang dilakukan penulis adalah Penelitian Tindakan Kelas (PTK) yang mengacu kepada tindakan guru ketika melaksanakan pembelajaran sebagai upaya untuk memperbaiki kegiatan pembelajaran yang telah dilaksanakan. Hal ini sesuai dengan pernyataan Suharjono (Arikunto, 2006) yang mengemukakan bahwa "penelitian tindakan kelas adalah penelitian tindakan yang dilakukan di kelas dengan tujuan memperbaiki/meningkatkan mutu praktik belajar".

Desain PTK yang digunakan yaitu model siklus menurut Kemis dan Mc.Taggart (Suyanto, 1997 : 16) yaitu terdiri dari empat komponen yaitu :

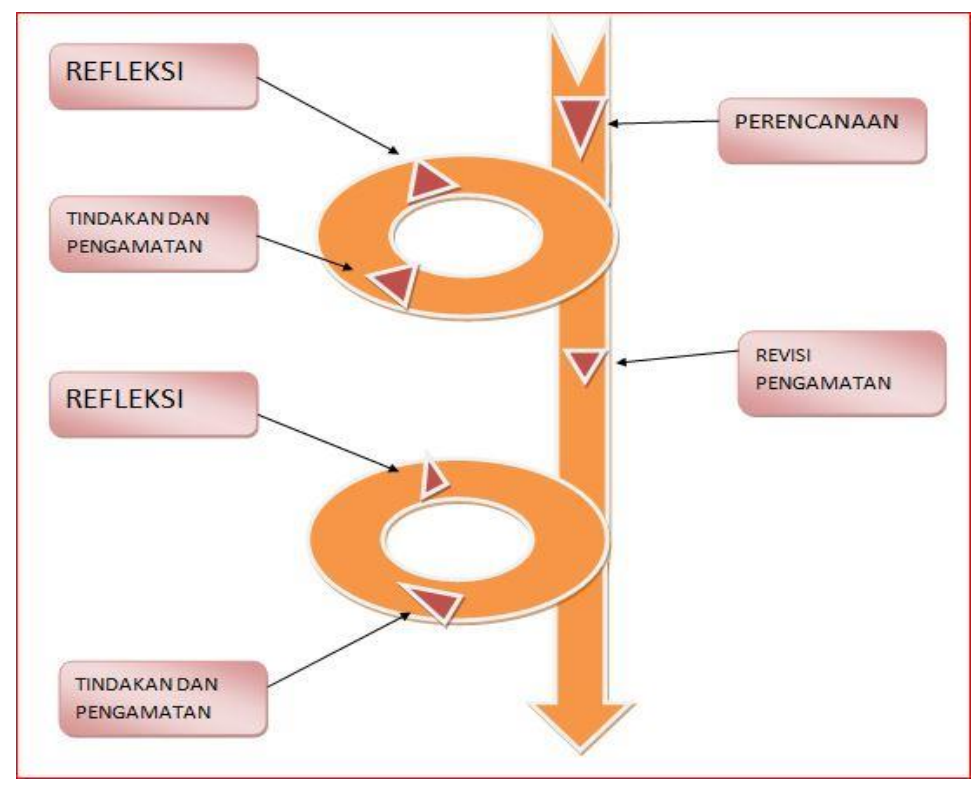

Gambar 1. Alur Penelitian Tindakan Kelas (Kasbolah, 1998). 
PTK ini dilaksanakan berdasarkan tahapan-tahapan sebagai berikut: "(1) merencanakan tindakan, (2) melaksanakan tindakan, (3) melaksanakan observasi, (4) melakukan refleksi." (Kasbolah, 1999). Keempat tahapan tersebut dirancang dan dilaksanakan untuk meningkatkan hasil belajar siswa melalui model pembelajaran discovery. Tahapan penelitian yang digunakan dalam penelitian ini berbentuk siklus, yang dibuat dalam bentuk rencana pelaksanaan pembelajaran. Tahapan-tahapan pada siklus pertama dirancang dari hasil refleksi kegiatan pembelajaran sehari-hari. Sedangkan tahapan-tahapan pada siklus kedua dirancang dari hasil refleksi siklus pertama. Maka dengan cara demikian diharapkan pada siklus kedua dapat meningkatkan hasil belajar siswa melalui model pembelajaran discovery pada siswa kelas VI SD Negeri 2 Girinata Kecamatan Dukupuntang.

Subjek penelitian tindakan kelas ini adalah siswa kelas VI SD Negeri 2 Girinata Kecamatan Dukupuntang Kabupaten Cirebon tahun ajaran 2017 - 2018 sebanyak 25 siswa. Dalam pengambilan subyek penelitian ini didasarkan pada kondisi kelas $1 \mathrm{~V}$ secara keseluruhan. Dalam penelitian ini asumsikan karakteristik dan kemampuan dianggap sama.

Data yang dikumpulkan yaitu hasil penilaian prestasi siswa dengan menerapkan metode konvensional, dan hasil pengamatan proses belajar yang meliputi metode pendekatan, materi pembelajaran dan performen guru/ instruktur

Data penelitian ini dianalisis dengan menggunakan pendekatan kuantitatif dan kualitatif secara bersama-sama. Pendekatan kualitatif digunakan untuk memberikan deskripsi tentang pandangan dan pendapat dari subyek penelitian. Pendekatan kuantitatif digunakan dengan cara mencatat peristiwa hasil prestasi belajar siswa sebelum adanya penelitian, kemudian diadakannya penelitian tindakan kelas pada siklus pertama dan kedua. Dengan pengelompokan data, maka akan ditemukan nilai rendah dan nilai tinggi serta ditemukan nilai rata-ratadari sebelum adanya penelitian tindakan kelas, ketika diadakan dan ada perbaikan.

\section{Hasil dan Pembahasan}

Kegiatan pembelajaran pada penelitian ini dilaksanakan dalam 2 siklus, masing-masing siklus terdiri dari studi pendahuluan, perencanaan, tindakan, observer dan refleksi kegiatan yang dilaksanakan. Pada setiap awal siklus dilakukan: a) identifikasi permasalahan menyangkut bahan pelajaran yang digunakan, strategi pembelajaran yang biasa digunakan, dengan menggunakan pendekatan konvensional, b). menyajikan materi pembelajaran "Nilai Juang dalam Proses Perumusan Pancasila", c). melakukan pengamatan dengan menggunakan observasi dan pemotretan, d). mengukur dampak pendekatan konvensional digunakan daftar aktivitas siswa.

Selama pelaksanaan penelitian penulis melakukan kolaborasi dengan guru lain dalam menyusun rencana penelitian, yang meliputi: 1) tujuan pembelajaran, 2) kompetensi dan materi pembelajaran, 3) strategi pembelajaran berupa Model pembelajaran, serta sumber belajar dan 4) evaluasi hasil belajar. Pada awal pembelajaran, observasi dilakukan terhadap guru membuka pelajaran seperti apersepsi terhadap materi yang akan dibahas dan memberikan motivasi kepada siswa.

Pada setiap siklus, dilakukan tes hasil belajar siswa setelah pembahasan suatu materi ajar selesai. Hasil tes dari semua siswa kelas VI SD Negeri 2 Girinata Kecamatan Dukupuntang Kabupaten Cirebon dapat dilihat pada tabel berikut: 
Tabel 1. Nilai Evaluasi Belajar Siswa pada Tiap Siklus

\begin{tabular}{|c|c|c|c|c|c|}
\hline \multirow{2}{*}{ No. } & \multirow{2}{*}{ Nama Siswa } & \multirow{2}{*}{$\mathrm{L} / \mathrm{P}$} & \multicolumn{3}{|c|}{ Nilai } \\
\hline & & & Awal & Siklus I & Siklus II \\
\hline 1 & Muh. Algar Farizki & $\mathrm{L}$ & 40 & 50 & 70 \\
\hline 2. & Muh. Leo Rivaldi & $\mathrm{L}$ & 70 & 80 & 90 \\
\hline 3. & Mutiara Karisma & $\mathrm{P}$ & 70 & 70 & 90 \\
\hline 4. & Mutiara Latifah & $\mathrm{P}$ & 70 & 70 & 90 \\
\hline 5. & Naila Sulistia Andini & $\mathrm{P}$ & 50 & 60 & 80 \\
\hline 6. & Nazril Nubaidillah & $\mathrm{L}$ & 70 & 70 & 90 \\
\hline 7. & Nazwa Amalia & $\mathrm{P}$ & 50 & 60 & 80 \\
\hline 8. & Nazwa Amelia R. & $\mathrm{P}$ & 70 & 80 & 90 \\
\hline 9. & Nurmala & $\mathrm{P}$ & 60 & 80 & 90 \\
\hline 10. & Loly Zherra Tripasma & $\mathrm{P}$ & 50 & 60 & 70 \\
\hline 11. & Opi Rositi & $\mathrm{P}$ & 70 & 70 & 80 \\
\hline 12. & Putri Winata & $\mathrm{P}$ & 60 & 80 & 80 \\
\hline 13. & Radit Firmansyah & $\mathrm{L}$ & 50 & 60 & 80 \\
\hline 14. & Rama Permana Aji & $\mathrm{L}$ & 50 & 60 & 80 \\
\hline 15. & Rizki Sugiarto & $\mathrm{L}$ & 70 & 80 & 90 \\
\hline 16. & Roma Sita & $\mathrm{L}$ & 60 & 70 & 80 \\
\hline & Ruanjani & $\mathrm{L}$ & 60 & 60 & 80 \\
\hline & Sabrina Andazhifa & $\mathrm{P}$ & 50 & 60 & 80 \\
\hline & Sintia Rahmadani & $\mathrm{P}$ & 60 & 80 & 90 \\
\hline & Siti Farida Untari & $\mathrm{P}$ & 50 & 60 & 80 \\
\hline 21. & Sri Mela Noviyanti & $\mathrm{P}$ & 70 & 80 & 90 \\
\hline 22. & Tiana Aninda & $\mathrm{P}$ & 50 & 50 & 70 \\
\hline 23. & Varel Dwi Nanda & $\mathrm{P}$ & 60 & 80 & 90 \\
\hline 24. & Vina Renatasari Adtya & $\mathrm{P}$ & 70 & 70 & 90 \\
\hline 25. & Yuni Agnia & $\mathrm{P}$ & 50 & 60 & 70 \\
\hline \multicolumn{2}{|c|}{ Jumlah } & & 1420 & 1710 & 2010 \\
\hline \multicolumn{2}{|c|}{ Rata - Rata } & & 58.68 & 68.42 & 82.36 \\
\hline \multicolumn{2}{|c|}{ Deskripsi } & & & $\begin{array}{l}\text { Belum } \\
\text { tuntas }\end{array}$ & tuntas \\
\hline
\end{tabular}

Tingkat pencapaian penguasaan materi PKn tentang "Nilai Juang dalam Proses Perumusan Pancasila” pada Awal mencapai rata-rata 58,68 pada Siklus I meningkat mencapai rata-rata 68,42, dan pada Siklus II terjadi peningkat yang ciukup signifikan yaitu mencapai rata-rata 82,36. Hasil evaluasi dari kerja kelompok dalam pembahasan materi "Nilai Juang dalam Proses Perumusan Pancasila" pada siklus I memperoleh rata-rata 72,5 dan pada siklus II naik menjadi 87,5 .

Dari data hasil pembahasan secara kuantitatif terhadap hasil evaluasi belajar PKn pada materi "Nilai Juang dalam Proses Perumusan Pancasila" yaitu hasil awal menunjukkan skor ratarata sebesar 58,68. Hasil pada siklus I naik menjadi skor rata-rata sebesar 68,42. Hasil pada siklus II naik menjadi skor rata-rata sebesar 82,36.

Dengan demikian, meningkatnya nilai dari hasil evaluasi pelajaran PKn pada materi "Nilai Juang dalam Proses Perumusan Pancasila" pada tiap siklusnya, berarti pemahaman siswa Kelas VI SD Negeri 2 Girinata Kecamatan Dukupuntang 1 Jagapura Lor pada materi tersebut menunjukkan adanya peningkatan yang cukup signifikan. Hal ini dapat dilihat melalui diagram grafik.

Hasil temuan secara kualitatif dalam penelitian tindakan kelas yang telah dilakukan pada siklus I dan siklus II yaitu aktivitas siswa dalam mengikuti kegiatan pembelajaran PKn pada 
materi "Nilai Juang dalam Proses Perumusan Pancasila", diantaranya siswa menyimak materi pembelajaran terlihat serius, interaksi siswa dalam kelompok terlihat aktif dan membahas lembar kerja, siswa yang mengajukan pertanyaan dan menjawab permasalahan yang diajukan oleh guru cukup meningkat, dan keberanian siswa dalam mengemukakan pendapat dilakukan oleh setiap kelompok dengan penuh antusias .

\section{Kesimpulan}

Berdasarkan penjelasan di atas dapat disimpulkan bahwa hipotesis tindakan terbukti, yaitu dengan menerapkan Model Pendekatan Discovery dapat Meningkatkan Pemahaman siswa dalam belajar PKn pada materi "Nilai Juang dalam Proses Perumusan Pancasila" di Kelas VI SD Negeri 2 Girinata Kecamatan Dukupuntang Kabupaten Cirebon.

\section{Daftar Pustaka}

Ariani, P. \& Wachidi. (2019). Penerapan Model Pembelajaran Discovery Learning Untuk Meningkatkan Keaktifan Dan Prestasi Belajar Ppkn Siswa Kelas VII SMPN 8 Rejang Lebong. DLADIK : Jurnal Ilmiah Teknologi Pendidikan, 8(1), 78-87.

Arikunto, S. (2006). Prosedur Penelitian Suatu Pendekatan Praktik. Jakarta: Rineka Cipta.

Depdiknas. (2006). Kurikulum Tingkat Satuan Pendidikan. Jakarta : Depdiknas.

Hanafi. (2016). The Effect of Discovery Learning Method Application on Increasing Students' Listening Outcome and Social Attitude. Dinamika Ilmu, 16(2), 291-306.

Illahi, MT. (2012). Pembelajaran Discovery Strategy dan Mental. Vocational Skill. Jogjakarta: Diva Press.

Kasbolah (1998). Penelitian Tindakan Kelas. Malang; Depdikbud.

Kurniasih, I. \& Sani, B. (2014). Implementasi Kurikulum 2013 Konsep dan Penerapan. Surabaya: Kata Pena.

Laksana, DS. (2018). Implementasi Model Discovery learning dalam Meningkatkan Prestasi Belajar Siswa Kelas IV Madrasah Ibtidaiah (MI) Al-Ma'arif Gendingan Kec. Kedungwaru Kab. Tulungagung. JIP:Jurnal Ilmiah PGMI, 4(1), 68-80.

Purwini. (2019). Penggunaan Discovery Learning Untuk Meningkatkan Hasil Belajar Pkn Siswa Kelas VIII SMP. Paedagoria, 10(1), 8-15.

Reinata. (2019). Pengaruh Penerapan Model Discovery Learning Terhadap Hasil Belajar Siswa Pada Pembelajaran Pkn di Kelas V SDN 02 Aur Kuning Bukittinggi. Jurnal Inovasi Pendidikan dan Pembelajaran Sekolah Dasar, 3(2), 13-24.

Somantri, MN. (2001). Menggagas Pembaharuan Pendidikan IPS. Bandung: Remaja Rosda Karya.

Sujana, A. (2014). Pendidikan IPA. Bandung: Rizqi Press.

Sulfemi, WB. \& Yuliana, D. (2019). Penerapan Model Pembelajaran Discovery Learning Meningkatkan Motivasi Dan Hasil Belajar Pendidikan Kewarganegaraan. Jurnal Rontal Keilmuan PKn. 5(1). 17-30.

Suyanto.(1997). Pedoman pelaksaaa penelitian kelas. Jakarta: Dirjen Dikti. 